\title{
DO ADDITIONAL BANDS (COASTAL, NIR-2, RED-EDGE AND YELLOW) IN WORLDVIEW-2 MULTISPECTRAL IMAGERY IMPROVE DISCRIMINATION OF AN INVASIVE TUSSOCK, BUFFEL GRASS (CENCHRUS CILIARIS)?
}

\author{
Victoria Marshall ${ }^{\mathrm{a}^{*}}$, Megan Lewis ${ }^{\mathrm{a}}$, Bertram Ostendorf ${ }^{\mathrm{a}}$ \\ ${ }^{a}$ School of Earth and Environmental Sciences, The University of Adelaide, POB 1 Glen Osmond 5064, South Australia \\ (firstname.lastname@adelaide.edu.au )
}

Commission VIII, WG VIII/6

KEY WORDS: Vegetation, Mapping, Classification, Targets, Multispectral

\begin{abstract}
:
Our goals is to determine if Worldview-2 8-band multispectral imagery can be used to discriminate an invasive grass species namely, Buffel grass (Cenchrus ciliaris) in the subtropical arid parts of central Australia and whether it offers a tangible improvement on 4-band (visible and near infra red) multispectral imagery. A Worldview-2 scene was acquired for a $10 * 10 \mathrm{~km}$ area just west of Alice Springs in central Australia following heavy rains of early Summer. Mixture Tuned Matched Filtering was used to classify the image. Target and background spectra were selected in the field and extracted from the image. Linear discriminate analysis (LDA) was used to examine the spectral separability of each group of the target/ background spectra. The importance of the additional spectral bands on the image classification was assessed by running LDA for both 8 and 4 bands (red, green, blue and NIR). LDA did not indicate improved separability between groups when additional spectral bands were applied. Preliminary classification results indicate that Buffel grass (Cenchrus ciliaris) is detected with an omission error $44 \%$, commission error of $11.8 \%$ and overall accuracy of $59.5 \%$. We were surprised that the additional spectral bands did not improve spectral separability and in part attribute this to the high degree of variance we observed within groups of spectra, which was particularly observable in the NIR2 and Yellow bands. The analyses may be significantly improved by acquiring imagery following the first big rains at the end of the dry season. At this time, phonological differences between our focal species and the surrounding native vegetation should be maximised. We suspect that Worldview-2 will offer even greater potential for the discrimination of Buffel grass under these conditions, being able to fully utilise the yellow-band in particular.
\end{abstract}

\section{INTRODUCTION}

Grass invasions represent a significant threat to biodiversity and in their aggregate may impact global aspects of ecosystem function (D'antonio and Vitousek, 1992). This is largely due to their impact on native wildfire regimes which typically increase in frequency and intensity where grass was previously absent. Early detection of new invasions fronts is critical for effective control. Remote sensing presents as an ideal mode for mapping and monitoring invasion as it affords a landscape scale view of the invasion and can be cost effective compared with laborious field work. However, due to the often indistinct spectra of grasses and varying sizes of stands, accurate detection using remote sensing is challenging. It requires careful consideration of the species distinctive features, smallest unit of invasion, seasonal growth, and habit as well as characteristics of the sensor employed.

Although successfully applied to species-level discrimination where the target-species covered a broad extent and possessed distinct phonological characteristics (Arzandeh and Wang, 2003), aerial photography as well as long-established multispectral sensors such as Landsat and SPOT have been described as inadequate for discriminating between grasses (Gray et al., 2008, Stitt et al., 2006). Hyperspectral sensors have been proven to deliver a high degree of accuracy for species-level discrimination (Gray et al., 2009, Lass et al., 2002) but the advantages of hyperspectral sensors do not always justify the high cost and large volumes of redundant data requiring expert interpretation; as a result it is impractical for most weed management authorities to utilise this imagery. The recently launched (January 2010) Digital Globe Sensor Worldview-2 offers a middle ground between high spatial and high spectral resolution which has been lacking. It provides high spatial resolution $(2 \mathrm{~m}$ multispectral, $0.5 \mathrm{~m}$ pan-sharpened) as well as 8 spectral bands specifically: short-wave blue $(427-458 \mathrm{~nm})$, blue (478- $515 \mathrm{~nm})$, green $(546-586 \mathrm{~nm})$, yellow $(608-632$ $\mathrm{nm})$, red (659- $694 \mathrm{~nm})$, red-edge (724- $749 \mathrm{~nm})$, NIR-1 (833- $901 \mathrm{~nm})$ and NIR-2 (949- $1043 \mathrm{~nm})$. Our aim is to determine if Worldview-2 imagery can be used to discriminate an invasive grass species namely, Buffel grass (Cenchrus ciliaris) in the subtropical arid parts of central Australia and whether it offers a tangible improvement on 4-band (visible and near infra red) multispectral imagery. 


\section{METHODS}

\subsection{Focal Species}

Buffel grass (Cenchrus ciliaris) is a C4 African perennial tussock grass hailed for its resistance to drought and heavy grazing in sub-tropical semi-arid rangelands throughout Australia and the Americas. However, it can rapidly invade non-target environments, increasing the frequency and intensity of wildfire threatening biodiversity conservation as well as residential areas. Efforts are now being made to prevent further spread of this highly invasive and versatile species. Buffel grass has highly varied morphological and physiological characteristics. It spreads by seed both sexually and asexually and vegetatively via rhizomes and stolons. The result of this is that Buffel grass has a range of forms and can be observed growing in dense monotypic stands as well as small clumps and lone tussocks throughout the landscape. Individual tussocks can live up to 20 years, reaching heights of between $20-150 \mathrm{~cm}$ and produce inflorescence ranging in colour from beige to dark purple. Older plants tend to have a less vibrantly green leaves and typically hold dead leaf at the base of the tussock (Figure 1).

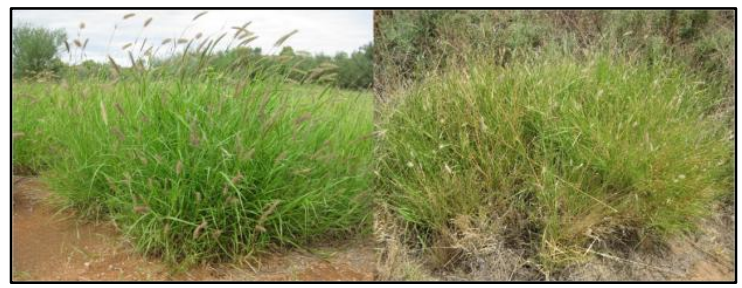

Figure 1: LEFT Juvenile plant growing in creek line; RIGHT mature plant growing at roadside (Photographs by Victoria Marshall, northern South Australia)

\subsection{Study area}

Our study site is a $10 * 10 \mathrm{~km}$ area located one kilometre west of Alice Springs, in central Australia (Figure 2). Selected to represent the great diversity of landscapes present in central Australia, the scene covers 3-4 peaks of the MacDonnell Ranges, the townships of Larapinta, pastoral leases, dry creeks and wildlife protected areas. Vegetation types which dominate the scene include Witchetty Bush or Mulga woodlands, Ironwood Acacia woodlands and Spinifex grasslands. This sub-tropical arid region typically receives sporadic summer rains which can support dense infestations of Buffel grass. The grass was sown in and around Alice Springs Airport (Figure 2) in the early 1970's to prevent dust storms, and has spread out into the neighbouring regions. Locals have a strong understanding of its presence in the highly varied landscape. In this areas there are known dense infestations along watercourse, associated alluvial soils and roadsides; sparse infestation on foot hills, becoming sparser as it moves further up the hill face; fire affected regions where Buffel grass is emerging first on ash beds as well as protected sites where the grass is actively controlled.

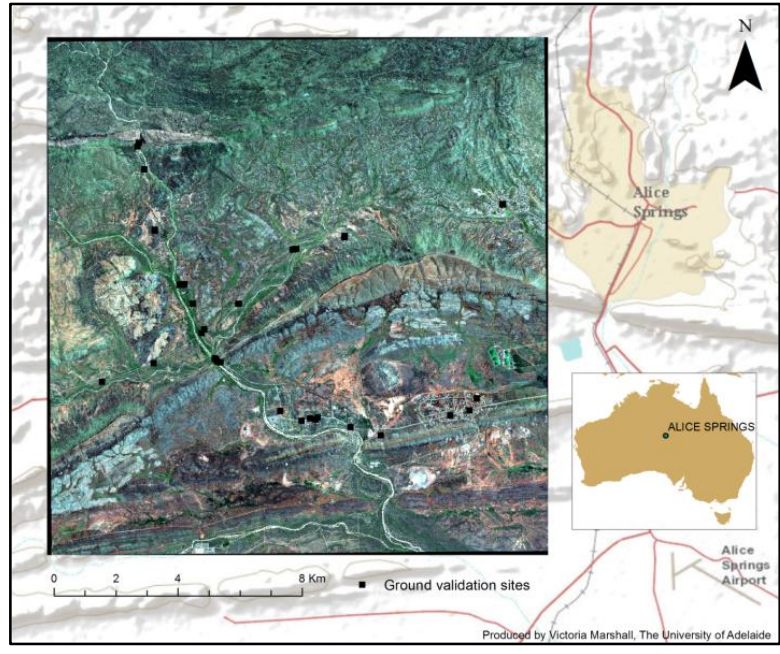

Figure 2: Study site $1 \mathrm{~km}$ west of Alice Springs in central Australia. Worldview-2 imagery displayed in true colour covering the total extent of the study site. Ground validation sites are marked (black squares).

\subsection{Image acquisition and pre-processing}

The imagery was acquired on the 22 January 2011 in the middle of the wet season following approximately $80 \mathrm{~mm}$ of rain over the preceding month. The region had also been exposed to record high volumes of rain between August and November 2010 due to tropical cyclones and floods in Northern Australia. Thus, high densities of all ephemeral plants were expected. The cloud-free imagery was captured at 1:30 in the afternoon at an off-nadir angle of 13 degrees. We corrected for atmospheric effects using Fast- Line-of-sight Atmospheric Analysis of Spectral Hypercubes (FLAASH) in ENVI 4.8. A Mid-Latitude Summer Atmospheric Model, Rural Aerosol Model and an Initial Visibility of $40 \mathrm{~km}$ were applied. The Zenith Angle was calculated by taking the mean-off-nadir angle from 180 .

\subsection{Image segmentation: Extracting vegetation}

Normalised Difference Vegetation Index (NDVI) was applied to the image based on Worldview-2 Red and NIR-2 bands. We adopted this traditional approach to vegetation extraction in response to the high levels of photosynthetically active vegetation present in the region. Based on NDVI values, a generous mask (NDVI values: 0.3- 2.5) was applied to extract vegetation components of land cover from the image.

\subsection{Principle Component Analysis}

To identify the key factors contributing to variation in the image a principal component analysis (PCA) was applied. This analysis linearly transforms correlated bands into uncorrelated components that represent variation in the data, reducing the redundancy in the data, while retaining all 8 bands. The result in this case is 8 principal components, where the first three components represent approximately $95 \%$ of the variation in the image (Figure 3). Based on eigenvectors we can see that principal component (PC) one, represents overall albedo, PC-2 captures green vegetation and PC-3 captures areas 
where there is a strong contrast between Red and the other wavebands.

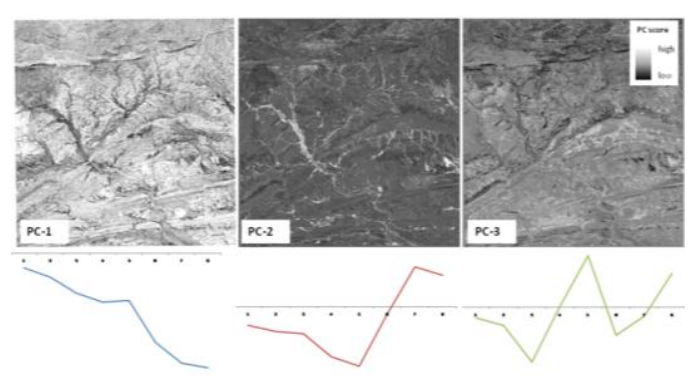

Figure 3: The first three principal components for the vegetation image. Eigenvector values for each PC are presented below the associated image. These graphs illustrate the weighting of each WV-2 band (from 1 to 8 ) expressed in each principal component. For example, Eigenvectors for PC-2 show low levels in band 5 (red) and high in the NIR bands 7 and 8, thus land cover components with a strong difference between red and near infra red, such as actively growing vegetation are highlighted in this image.

\subsection{Spectral Separability}

Results of the PCA of the NDVI masked vegetation were used in conjunction with strong local knowledge of the area to extract reference spectra from the original Worldview-2 scene for Buffel grass in various conditions (lush, grazed and burnt) and broadly categorised surrounding vegetation including mulga, tree and native. Between 5 and 10 spectra for each vegetation cover type were collected (Figure 4). Their spectral separability was examined using a linear discriminate analysis (LDA). LDA is a method used to discriminate between groups of samples based on a linear transformation of predictor variables, which in this case are the eight image bands (Rencher, 2002). LDA was cross validated using the leave-one-out technique (Rencher, 2002). To examine the importance of the additional bands on the classification, the LDA was performed for 4 bands (blue, green, red and NIR1) as well as the full 8 bands. Outlying samples were excluded and spectral-groups were averaged prior image classification.

\subsection{Image classification}

Image classification was conducted using the ENVI 4.8 Target Detection Wizard. Lush Buffel grass was used as the target spectra. Background spectra were also identified as native, mulga and tree and included buffel grass "grazed" and "burnt". A Minimum Noise Fraction Transformation was applied to the imagery. For target detection we chose to explore the use of Mixture Tuned Matched Filtering (MTMF), a method often applied to hyperspectral imagery (Williams and Hunt, 2002). The MTMF produced two grey scale images: Matched Filtering Score (MFS) and Infeasibility Score (IS). Areas most likely to be Buffel grass will have a high MFS and a low infeasibility score. Therefore, we divided MF by Infeasibility to produce a grey scale image of spectral likeness to Buffel grass, where higher values are the most like Buffel grass. We classified the image based on thresholds of this score to produce a map that indicates Buffel grass absence (MFS/IS <0.06), Buffel grass presence - division 1 (MFS/IS $>0.1$ ) and Buffel grass presence - division 2 (MFS/IS >0.06, <0.1), where division 1 is most like Buffel grass.

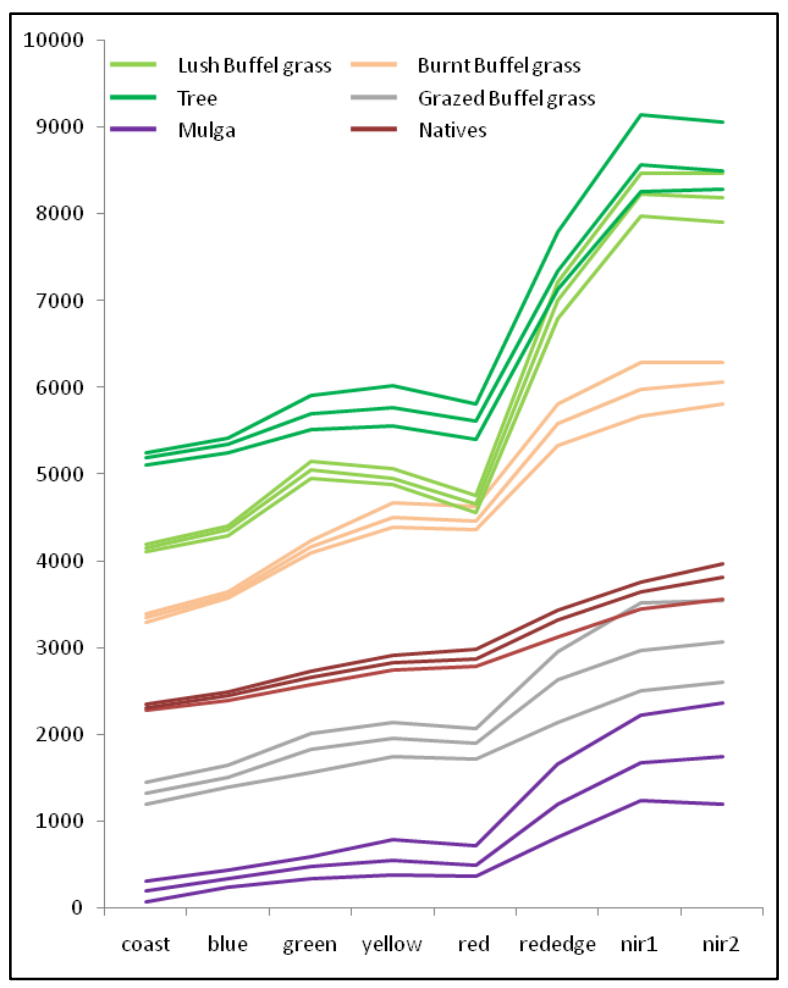

Figure 4: Mean, Maximum and Minimum reflectance $(\mathrm{nm})$ for each spectral group collected from Worldview-2 scene obtained 22 Jan 2011 over a 10x10km area $1 \mathrm{~km}$ west of Alice Springs, Australia. Each spectral grouping is offset by $1000 \mathrm{~nm}$. Spectral groups include Lush Buffel grass, Tree, Mulga, Burnt Buffel grass, Grazed Buffel grass and Natives.

\subsection{Ground Validation Data}

To validate the classified image, ground data was collected on the 20-22 of March 2011, two months after image capture. The presence or absence of Buffel grass at low (1-34\%), medium (35-84\%), and high (85-100\%) densities was recorded at points accessible by roads throughout the study area. Each record represented a circular area with a diameter of approximately 10 meters. This diameter was selected to account for the spatial accuracy of the Worldview-2 product (10.16 metres) as well as of the Garmin GPS receiver $(2 \mathrm{~m})$. Approximately 40 records were collected (Figure 2).

\section{RESULTS}

\subsection{Spectral Separability of Buffel grass from}

\section{surrounding vegetation using 4 and 8 bands}

Spectra selected showed high separability based on LDA for both 4 and 8 band analysis. Predictions based on 
LDA (Table 1) are marginally stronger (2\%) using 4 bands compared with 8 bands. Predictions based on either 4 or 8 bands indicate that native may be over classified at a rate of $30 \%$ as grazed Buffel grass or mulga. For predictions based on 8-bands there is an additional error; Burnt Buffel grass may be misclassified at a rate of $20 \%$ as Grazed Buffel grass. Linear discriminators LD1, LD2, and LD3 combined represent greater than $80 \%$ of the trace in both analyses. By examining the contribution of each spectral band to the LD's we can see that in this instance the visible part of the spectrum is the most important for discriminating between vegetation types (Table 2). Blue and Green bands are particularly significant, with Infrared contributing least to the discrimination.

Table 1: Predictions made based on the LDA using 4 (red, blue, green, NIR1) and 8 bands of the Worldview-2

imagery to discriminate between Buffel grass from various other vegetation types. Correct classifications are presented in green, misclassifications are presented in red.

\begin{tabular}{lcccccc}
\hline & Burnt & Grazed & Lush & Mulga & Natives & Tree \\
\hline \multicolumn{7}{l}{ Prediction based on 4-Bands (blue, green, red, NIR1) } \\
\hline Burnt Buffel grass & 5 & 0 & 0 & 0 & 0 & 0 \\
\hline Grazed Buffel grass & 0 & 3 & 0 & 0 & 2 & 0 \\
\hline Lush Buffel grass & 0 & 0 & 6 & 0 & 0 & 0 \\
\hline Mulga & 0 & 0 & 0 & 6 & 1 & 0 \\
\hline Natives & 0 & 0 & 0 & 0 & 7 & 0 \\
\hline Tree & 0 & 0 & 0 & 0 & 0 & 6 \\
\hline Prediction based on 8-Bands & & & & & \\
\hline Burnt Buffel grass & 4 & 1 & 0 & 0 & 0 & 0 \\
\hline Grazed Buffel grass & 0 & 3 & 0 & 0 & 2 & 0 \\
\hline Lush Buffel grass & 0 & 0 & 6 & 0 & 0 & 0 \\
\hline Mulga & 0 & 0 & 0 & 6 & 1 & 0 \\
\hline Natives & 0 & 0 & 0 & 0 & 7 & 0 \\
\hline Tree & 0 & 0 & 0 & 0 & 0 & 6 \\
\hline
\end{tabular}

Table 2: Contribution of each spectral band to linear discriminatORS 1,2 and 3 for LDA using 4 (red, blue, green, NIR1)and 8 bands of the Worldview-2 imagery to discriminate between Buffel grass from various other vegetation types

\begin{tabular}{llll}
\hline & \multicolumn{1}{l}{ LD1 } & LD2 & LD3 \\
\hline 4-Bands (blue, green, red, NIR1) & & \\
\hline Blue & $\mathbf{- 0 . 0 0 8 0 3}$ & $\mathbf{- 0 . 0 1 9 7 7}$ & $\mathbf{0 . 0 1 3 0 3 4}$ \\
\hline Green & $\mathbf{0 . 0 0 9 8 8 6}$ & 0.005243 & -0.02967 \\
\hline Red & 0.005438 & $\mathbf{0 . 0 1 1 7 0 4}$ & $\mathbf{0 . 0 1 3 1 1 9}$ \\
\hline NIR1 & -0.00564 & 0.000486 & 0.004503 \\
\hline *Proportion of Trace & 0.627 & 0.248 & 0.1189 \\
\hline 8-Bands & & & \\
\hline Coast & -0.00079 & $\mathbf{0 . 0 2 2 5 5}$ & -0.00981 \\
\hline Blue & $\mathbf{- 0 . 0 1 7 3 2}$ & 0.01051 & -0.00065 \\
\hline Green & $\mathbf{0 . 0 2 1 2 9 4}$ & $\mathbf{- 0 . 0 2 1 2 5}$ & $\mathbf{0 . 0 2 9 9 5 6}$ \\
\hline Yellow & 0.003094 & -0.00596 & -0.00037 \\
\hline Red & 0.006336 & -0.00443 & $\mathbf{- 0 . 0 1 6 2 8}$ \\
\hline Red Edge & -0.00952 & 0.008127 & -0.00191 \\
\hline
\end{tabular}

\begin{tabular}{llll}
\hline NIR1 & -0.00633 & 0.000283 & -0.00838 \\
\hline NIR2 & 0.005092 & -0.00336 & 0.004997 \\
\hline *Proportion of Trace & 0.5579 & 0.3043 & 0.1188 \\
\hline
\end{tabular}

\subsection{Image classification}

The classified image (Figure 5) indicates that Lush Buffel grass tends to occur on rich alluvial soils surrounding creek lines and drainage depressions. Spectral matching was strongest surrounding the major creek line which runs north-south through the image. Enlargement $A$ presented in Figure 5 shows where this major creek line passes through a natural gap in the ridge. Here is clear that the Buffel grass, division 1 classified unit, successfully discriminates highly photosynthetically active vegetation from trees present in the dry creek, where the division 2 did not separate the trees, which are easily recognisable to the eye. Both divisions 1 and over classify highly photosynthetically active vegetation, as can be seen in enlargement $\mathrm{B}$, which depicts an oval in the township, which is not sown with Buffel grass.

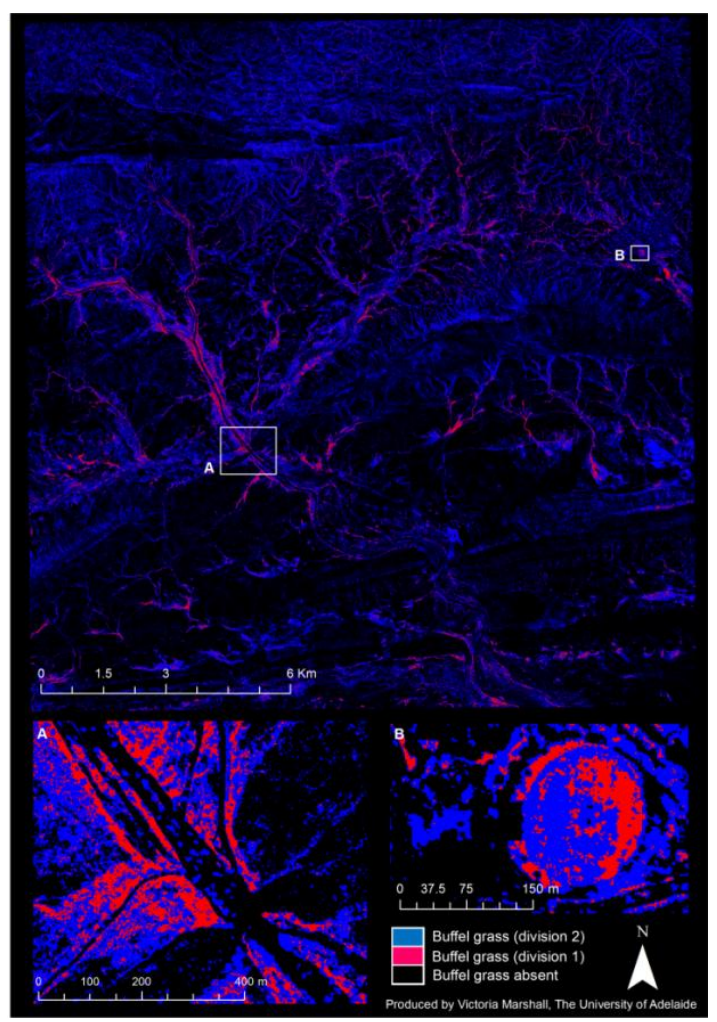

Figure 5: Worldview-2 image classified using MTMF target detection and reduced, based on band thresholds, to three classes Buffel grass absence (black), presence (division 1) (red) and presence (division 2) (blue) where division 1 is mostly likely to be Buffel grass.

\subsection{Accuracy Assessment}

The overall accuracy of the imagery classification was $59 \%$ (Table 3). For this assessment the Buffel grass presence division 1 and 2 were amalgamated as we judged this was appropriate based on our knowledge of the area. 
Table 3: Accuracy assessment of Buffel grass mapping comparing on ground data to Worldview-2 image classification of Buffel grass presence and absence

\begin{tabular}{|c|c|c|c|c|c|c|c|}
\hline & & \multicolumn{3}{|c|}{ Imagery } & \multirow{2}{*}{$\begin{array}{l}\text { Omiss } \\
\text { ions }\end{array}$} & \multirow{2}{*}{$\begin{array}{l}\text { Commis } \\
\text { sions }\end{array}$} & \multirow{2}{*}{$\begin{array}{l}\text { Mapping } \\
\text { Accuracy }\end{array}$} \\
\hline & & $\begin{array}{l}\text { Abs } \\
\text { ent }\end{array}$ & $\begin{array}{l}\text { Pres } \\
\text { ent }\end{array}$ & $\begin{array}{l}\text { Total } \\
\text { Possible }\end{array}$ & & & \\
\hline \multirow{3}{*}{ 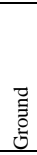 } & $\begin{array}{l}\text { Abs } \\
\text { ent }\end{array}$ & 6 & 2 & 8 & 25.0 & 50 & 50 \\
\hline & $\begin{array}{l}\begin{array}{l}\text { Pres } \\
\text { ent }\end{array} \\
\end{array}$ & 15 & 19 & 34 & 44.1 & 11.7 & 44.1 \\
\hline & $\begin{array}{l}\text { Tota } \\
1 \\
\end{array}$ & 21 & 21 & 42 & & & \\
\hline
\end{tabular}

\section{DISCUSSION}

Monitoring grass invasion is crucial for effective control. Remote sensing presents as a cost effective means to do this. However, for species which are spectrally similar to their surroundings remote detection can be challenging. We have presented a method for detecting lush (highly photosynthetic) Buffel grass in a diverse central Australian environment using 8-band multispectral imagery, Worldview-2. We used NDVI to mask out nonphotosynthetic land cover and apply Mixed Mixture Tuned Matched Filtering to classify the image. Absence of Buffel grass is mapped with $50 \%$ accuracy, and error is mostly attributed to Commission. Presence of Buffel grass is mapped with $44.1 \%$ accuracy, omission error $44.1 \%$ while the commission error is $11.7 \%$. It is likely that some of the error in the classification of Buffel grass presence relates to the 2 month time lag between image capture and field data collection, during which there was considerable rainfall and highly active growth of all ephemeral plants. In addition, Buffel grass can be observed growing beneath trees particularly Mulga trees in the field. This may result in under classification of Buffel grass on the imagery.

To our surprise, linear discriminate analysis of spectra using 8-bands and 4-bands (blue, green, red and NIR1) of the Worldview-2 imagery does not indicate a benefit in using the additional 4 bands. This is probably due to a high level of variation within the spectral groups, which is particularly observable in the NIR2 and Yellow bands (Figure 4). In this instance, we feel that that the 8-bands may significantly improve spectra separability, under different seasonal conditions. Here, we examined an image dominated by high volumes of photosynthetically active, green vegetation, and thus Green and Blue bands present as the most effective discriminators. We consider that had the image been captured during a dry season, the Yellow band may have been a significant contributor to the effective discrimination of Buffel grass from surrounding vegetation.

\section{ACKNOWLEDGEMENTS}

This research was undertaken as a part of $\mathrm{PhD}$ studies at the University of Adelaide, Australia, supported by an
Australian Postgraduate Award and funding from the Alinitjara Wiluara Natural Resource Management Board. Thanks to the many valued individuals who shared their knowledge, especially Peter Latz whose personal tours of the Alice Springs landscape where invaluable and my $\mathrm{PhD}$ supervisors Associate Professors Dr. Megan Lewis and Dr. Bertram Ostendorf. This imagery obtained free of charge via the Digital Globe 8-Band Challenge 2010.

\section{REFERENCES}

Arzandeh, S. \& Wang, J. F. 2003. Monitoring the change of Phragmites distribution using satellite data. Canadian journal of remote sensing, 29, 24-35.

D'antonio, C. M. D. \& Vitousek, P. M. 1992. Biological Invasions by Exotic Grasses, the Grass/Fire Cycle, and Global Change. Annual Review of Ecology and Systematics, 23, 63-87.

Gray, C. J., Shaw, D. R. \& Bruce, L. M. 2009. Utility of Hyperspectral Reflectance for Differentiating Soybean (Glycine max) and Six Weed Species. Weed Technology, 23, 108-119.

Gray, C. J., Shaw, D. R., Gerard, P. D. \& Bruce, L. M. 2008. Utility of Multispectral Imagery for Soybean and Weed Species Differentiation. Weed Technology, 22, 713-718.

Lass, L. W., Thill, D. C., Shafii, B. \& Prather, T. S. 2002. Detecting spotted knapweed (Centaurea maculosa) with hyperspectral remote sensing technology. Weed Technology, 16, 426-432.

Rencher, A. C. 2002. Methods of Multivariate Analysis, Canada, John Wiley and Sons, Inc. .

Stitt, S., Root, R., Brown, K., Hager, S., Mladinich, C., Anderson, G. L., Dudek, K., Bustos, M. R. \& Kokaly, R. 2006. Classification of leafy spurge with Earth Observing-1 Advanced Land Imager. Rangeland Ecology \& Management, 59, 507-511.

Williams, A. P. \& Hunt, E. R. 2002. Estimation of leafy spurge cover from hyperspectral imagery using mixture tuned matched filtering. Remote Sensing of Environment, 82, 446-456. 